\title{
Organisational Support and Its Influence on Teachers Job Satisfaction and Job Performance in Limpopo Province of South Africa
}

\author{
Richard Chinomona \\ University of the Witwatersrand, School of Economics and Business Sciences, South Africa \\ Email:rchinos@hotmail.com \\ Maxwell Sandada \\ University of Zimbabwe, Graduate School of Business Management, South Africa
}

Doi:10.5901/mjss.2014.v5n9p208

\begin{abstract}
The importance of organisational support is increasingly being recognized because of its potential positive influence on employee performance. However, studies that seek to investigate the influence of organisational support on the teachers' job satisfaction and consequently their workplace performance at high school level have largely remained scant, particularly in developing countries of Southern Africa. Therefore, the primary objective of this study is to fill this void. Three research hypotheses are posited and a sample data of 162 collected from the Limpopo Province of South Africa is used to empirically test the hypotheses. The results of this study show that, organisational support positively influences teachers'job satisfaction and their job performance. Managerial implications of the findings are discussed and limitations and future research directions are indicated.
\end{abstract}

Keywords: Organisational support, job satisfaction, job performance.

\section{Introduction}

In recent years, organizational support has received an immense attention from practitioners and academics as businesses look for ways to improve employee performance (Noblet \& Rodwell, 2009). There is a general consensus among organizational and human resources researchers that organizational support is a significant predictor of employee outcomes namely job satisfaction and performance. For example Rhoades and Eisenberger (2002) found that organizational support positively impacts on job satisfaction while Miao (2011) also report a positive correlation between organizational support and job performance. In addition, literature has also proven the relationship between job satisfaction and job performance (Bowling, 2010; Way, Sturman \& Raab, 2010). Employees who are satisfied with their jobs tend to work hard, do extra work and become committed to the organisation (Bowling, 2010).

The review of literature revealed that despite the recognition that organizational support is a catalyst to employee outcomes of job satisfaction and performance, the relationship between these constructs in the education sector is scarce. As Malhotra and Mukhejee (2004) have observed, most of the research examining these relationships have been conducted in private organisations such as hotels, banks, insurance companies, and others (Way et al., 2010; Abdullah, Bilau, Enegbuma, Ajagbe \& Ali, 2011; Chiang \& Hsieh, 2012). Furthermore, most of these studies were carried out in American, European and Asian countries (Noblet \& Rodwell, 2009; Bowling, 2010; Miao, 2011) and a few of them were conducted in Africa (Abdullah et al., 2011). It may therefore be misleading to assume a-priori that the results found in these developed countries are applicable to developing countries and emerging economies like South Africa. The lack of a comprehensive model showing relationships between organizational support, job satisfaction and performance in the education sector is a major shortcoming. This undermines the development of interventions to retain and motivate teachers in order to improve the service which they provide.

In view of this identified research gap, the current study seeks to investigate the influence of organizational support on teacher job satisfaction and performance in the South African schools. The results would provide insights to education leaders on how to support teachers in order to improve the quality of teaching. The study would also make an important contribution by advancing the body of knowledge on organizational support, job satisfaction and performance in context of institutions of higher learning in South Africa. 
The rest of the paper is arranged as follows: A theoretical review, the theoretical framework and hypotheses will firstly be presented. Thereafter the methodology, data analysis and conclusions are discussed. The final section presents the managerial implications, limitations and recommendations for future research.

\section{Literature Review}

\subsection{Organisational Support}

Perceived organisational support means rewarding and meeting the socio-emotional needs of employees (Bilgin \& Demirer, 2012). It involves the mentorship activities such as employee counseling, challenging assignments for employees, employee protection, coaching employees, ensuring friendship amongst employees and role modeling (Baranik, Roling \& Eby, 2010). According to Rhoades and Eisenberger (2002) employees perceive that the business supports them if resources are provided voluntarily rather than availing resources after pressure from trade unions and government regulations on health and safety. Similarly, Chiang and Hsieh (2012) assert that perceived organizational support is the belief that the employer cares about the needs of employees. To show support, the authors propose that the organizational needs to consider employee opinions, goals and values, help the employees if they encounter problems and should forgive honest mistakes of employees. Educational institutions can support educators by creating career opportunities, by funding employee career development, by incentivizing employees who develop their careers and by providing time for those who are developing careers through study leaves, seminars, workshops and conferences (Amin, 2013). As Bilgin and Demirer (2012) and Rhoades and Eisenberger (2022) show, the components of perceived organizational support include training, autonomy, job security and safety, recognition, pay, promotion, fairness, and work conditions. The foregoing discussion suggests that perceived organizational support depends on the belief by teachers that their needs are voluntarily cared for.

\subsection{Teachers' job satisfaction}

Job performance, according to Abdullah et al. (2011) implies positive emotional state of an employee as a result of pleasurable job experiences. The sources of job satisfaction are appreciation, communication, co-worker relationship, fringe benefits, job conditions, nature of the work itself, nature of the organisation, organizational policies and procedures, pay, growth, promotion opportunities, recognition, security and supervision (Lu, Barriball, Zhang \& While, 2011). Markovits, Davis, Fay and Dick (2010) identified two dimensions of job satisfaction, namely extrinsic satisfaction and intrinsic satisfaction. While extrinsic satisfaction consists of satisfaction with pay, physical conditions and organizational policies and procedures, intrinsic satisfaction includes aspects such as creativity, achievement and accomplishment. According to Abdullah et al. (2011), it is crucial for organisations to make sure that employees are satisfied with their jobs because it results in positive outcomes such as high productivity and increased life gratification. Rhoades and Eisenberger (2002) stipulated that meeting the socio-emotional needs of employees leads to positive mood, feelings of competence and worth, increased interest in the job, thereby enhancing job satisfaction. This indicates that organisations can achieve competitive advantages if they create conditions that promote job satisfaction because employees become committed to their jobs and as a result are likely to engage in citizenship behaviours.

\subsection{Teacher job performance intention}

According to Chiang and Hsieh (2012), job performance means fulfilling specific job requirements, meeting job performance standards and expectations, one's effectiveness in the job and the ability to produce quality work. Miao (2011) identified the two categories of job performance which are role/task and discretionary/extra role performance. The role/task performance is the performance that is prescribed by the business which the employees are obligated to perform. On the other hand the extra role performance is the employee citizenship behavior which deals with extra role that is performed by the employee to support the role/task role and this depends on the employee's discretion. $\mathrm{Ng}$, Sorensen and Yim (2009) contend that the examples of the extra role performance are altruism (willingness to help colleagues), conscientiousness (willing to work extra hours), sportsmanship (not complaining about trivial issues), courtesy (involving others before taking action), and civic virtue (knowing things that affect the business). 


\section{Conceptual Framework and Hypotheses}

Based on review of literature, the conceptual model was developed as shown in Figure 1. Three basic constructs, which were discussed in the preceding section, make up the model. These constructs are organisational support, teacher's job satisfaction, and teacher's job performance intention. The relationships between the proposed constructs in the conceptual model are as follows, organisational support provides the starting point of the model, and it directly impacts on their job satisfaction and performance intention. Finally, satisfied teachers are likely to improve their performance. The hypotheses that were developed explain the relationships among the constructs in detail.

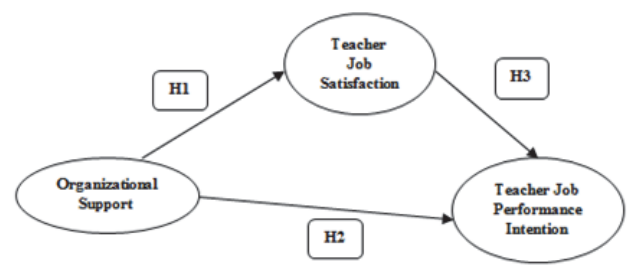

Figure 1: Conceptual Model

\subsection{Organisational support and job satisfaction}

Supporting employees brings pleasure in their jobs and this leads to job satisfaction (Bilgin \& Dimirer, 2012). As Baranik, Roling \& Eby, (2010) have shown, organizational support in the form of mentorship activities such as coaching, counseling, protection and challenging assignments positively influences job satisfaction. Rhoades and Eisenberger (2002) support the positive correlation between organizational support and job satisfaction by pointing out that due to pleasure at work employees go beyond assigned responsibilities. For example, they assist others, they protect the business from risks, become innovative, suggest constructive ideas and acquire skills that help the organisation. In studying the relationship between organizational support and job satisfaction in the Chinese context, Miao (2011) found a positive and significant association between the two variables. This suggests that supporting employees is imperative in order to enhance job satisfaction. Similarly, studies in Pakistan education institutions organizational support have indicated that in order to address job dissatisfaction, organizational support if one of the important factors. The authors further stipulate that low perceived institution support was associated with low educator job satisfaction. In addition, Chiang and Hsieh (2012) studied Taiwanese hotels and found a strong positive relationship between organizational support and job satisfaction. Therefore on that account the following hypothesis was developed:

H1: Organizational support is positive associated with high levels of teacher job satisfaction.

\subsection{Organisational support and job performance}

Literature has demonstrated that the relationship between organizational support and job performance is positive. For example, a meta- analysis of the relationship between perceived organizational support and job outcomes by Riggle, Edmondson and Hansen (2009) underscored a positive correlation between organizational support and job performance. Similar relationships were also found in Amin's (2013) study of the impact of organisational support on Pakistani academic employees' performance. The study reported that organizational support for career development and supervisory support are predictors of performance. In the Australian context, Noblet and Rodwell (2009) found that support from supervisors and colleagues represent important resources for enhancing police officers' commitment to the job and hence their job performance. Supported employees feel obligated to reciprocate by working extra hard in order to ensure organizational success (Miao, 2011). Based on the foregoing discussion the following hypothesis is advanced:

H2: Organisational support is positively associated with the teachers' job performance intention.

\subsection{Teacher job satisfaction and teacher job performance intention}

A great deal of empirical evidence produced by previous studies has demonstrated that the relationship between job satisfaction and performance is positive. Malhotra and Mukherjee (2004) support this relationship and contend that 
employees who are satisfied are more likely to produce quality service because of their willingness to contribute to the organizational success. In a similar vein, Bowling (2010) found that job satisfaction positively impacts on employee extrarole behaviours, hence satisfied employees are prepared to go an extra mile to improve their performance. A study of Asian hotels by Way et al. (2010) found evidence of a weak but positive relationship between job satisfaction and performance. The study recommends that to improve employee performance and satisfaction, managers need to ensure that employees understand job performance expectations and how performance is appraised and rewarded. In a similar study carried out on Italian privatized organisations by Borgogni, Russo, Petitta and Vecchione (2010), job satisfaction was found to be a predictor of performance. Abdullah et al. (2011) studied the Nigerian Small and Medium construction companies and also found a positive association between the two variables. On that account, the following hypothesis is formulated:

H3: Teacher job satisfaction is positively associated with teachers' job performance intention.

\section{Research Methodology}

\subsection{Sample and data collection}

The target population for the study was South African teachers in Limpopo Province. The sampling unit was the individual teacher. Students from the Vaal University of Technology were recruited as research assistants to distribute and collect the questionnaires. Of the total of 170 questionnaires distributed, 151 usable questionnaires were retrieved for the final data analysis, representing a response rate of 89 per cent. To eliminate differences in response patterns due to different reference points, all respondents were prompted to answer the questionnaire with reference to organisational support, job satisfaction and their performance, guided by the research assistants.

\subsection{Measurement Instrument and Questionnaire Design}

Research scales were operationalised on the basis of previous work. Proper modifications were made in order to fit the current research context and purpose. "Organisational support" and "job satisfaction" used five-item scale adapted from Chinomona (2012). Finally, "job performance" was measured using six-item scales adapted from Chiang and Hsein (2011). All the measurement items were measured on a five-point Likert-type scales that was anchored by $1=$ strongly disagree to $5=$ strongly agree to express the degree of agreement.

\subsection{Respondent Profile}

Table 1 presents the profile of the participants. The profile indicates that $56.7 \%$ of the participating were female and the remainder were male. $23.5 \%$ of the respondents were less than or aged 30 years old while the remainder were above 30 years. Also $67.3 \%$ of the respondents were Diploma holders while the reminder constituted the non-Diploma holders.

\section{Data Analysis}

\subsection{Structural Equation Modelling Approach}

In order to statistically analyze the measurement and structural models, this study used Smart PLS software for Structural Equation Modeling (SEM) technique (Ringle, Wende \& Will 2005). In SEM, the measurement model refers to the linkages between the latent variables and their manifest variables and the structural model captures the hypothesized causal relationships among the research constructs (Chin \& Newsted, 1999). Unlike AMOS and LISREL which are covariancebased approaches, Smart PLS is a regression based technique that originates from path analysis. Smart PLS has emerged as a powerful approach to study causal models involving multiple constructs with multiple indicators (Chinomona \& Surujal, 2012). Smart PLS - a component-based method, has an ability to model latent constructs that are uncontaminated by measurement error under conditions of non-normality. It has the ability to handle complex predictive models in small-to-medium sample sizes. Since the current study sample size is relatively small (150) Smart PLS was found more appropriate and befitting the purpose of the current study. In this respect, Bootstrapping resampling method was used to test the statistical significance of the relationships. This procedure entailed generating 200 sub-samples of cases randomly selected, with replacement, from the original data. Below is Table 2, presenting evidence on the reliability and validity of the measurement model. 


\subsection{Measurement Model}

To ensure convergent validity, the researcher checked if items loaded on their respective (a priori) constructs with loadings greater than 0.6 , while discriminant validity was checked by ensuring that there was no significant inter-research variables cross-loadings (Chin, 1998). As can be seen (Table 2), all items have loadings greater than 0.6 (i.e. ranging from 0.881 to 0.893 ), with no cross-loadings greater than 0.867 , while t-statistics derived from bootstrapping (200 resamples) suggest all loadings are significant at pb0.001. As such, this confirms that all the measurement items converged well on their respective constructs and therefore are acceptable measures.

Table 2: Accuracy Analysis Statistics

\begin{tabular}{|c|c|c|c|c|c|c|c|c|}
\hline \multicolumn{2}{|c|}{$\begin{array}{l}\text { Research } \\
\text { Construct }\end{array}$} & $\begin{array}{c}\text { LV Index } \\
\text { Value }\end{array}$ & $\begin{array}{c}\text { R-Squared } \\
\text { Value }\end{array}$ & $\begin{array}{c}\text { Cronbach's } \alpha \\
\text { value }\end{array}$ & $\begin{array}{c}\text { C.R. } \\
\text { Value }\end{array}$ & $\begin{array}{c}\text { AVE } \\
\text { Value }\end{array}$ & Communality & $\begin{array}{l}\text { Factor } \\
\text { Loading }\end{array}$ \\
\hline \multirow{5}{*}{ os } & OS 1 & \multirow{5}{*}{4.382} & \multirow{5}{*}{0.000} & \multirow{5}{*}{0.839} & \multirow{5}{*}{0.824} & \multirow{5}{*}{0.581} & \multirow{5}{*}{0.581} & 0.717 \\
\hline & OS 2 & & & & & & & 0.799 \\
\hline & OS 3 & & & & & & & 0.801 \\
\hline & OS 4 & & & & & & & 0.790 \\
\hline & OS 5 & & & & & & & 0.697 \\
\hline \multirow{5}{*}{ TJS } & TJS1 & \multirow{5}{*}{4.469} & \multirow{5}{*}{0.402} & \multirow{5}{*}{0.893} & \multirow{5}{*}{0.867} & \multirow{5}{*}{0.653} & \multirow{5}{*}{0.653} & 0.783 \\
\hline & TJS2 & & & & & & & 0.793 \\
\hline & TJS3 & & & & & & & 0.830 \\
\hline & TJS4 & & & & & & & 0.825 \\
\hline & TJS5 & & & & & & & 0.808 \\
\hline \multirow{6}{*}{ TJP } & $\overline{\text { TJP1 }}$ & \multirow{6}{*}{4.203} & \multirow{6}{*}{0.526} & \multirow{6}{*}{0.881} & \multirow{6}{*}{0.845} & \multirow{6}{*}{0.562} & \multirow{6}{*}{0.562} & 0.775 \\
\hline & TJP2 & & & & & & & 0.771 \\
\hline & TJP3 & & & & & & & 0.764 \\
\hline & TJP4 & & & & & & & 0.804 \\
\hline & TJP5 & & & & & & & 0.736 \\
\hline & TJP6 & & & & & & & 0.634 \\
\hline
\end{tabular}

Note: OS = Organisational Support; TJS = Teacher Job Satisfaction; TJP = Teacher Job Performance

According to Chin (1998), research variables should have an average variance extracted (AVE) of more than 0.5 and a composite reliability of more than 0.7 (convergent validity), and inter-construct correlations should be less than the square-root of the AVE (discriminant validity). As can be seen (Table 2), all constructs exceed these criteria, with AVE and CR generally equal or greater than 0.562 and 0.824 , respectively. Furthermore, as indicated in Table 3 , the squareroot of the lowest AVE is 0.82 and is greater than the highest inter-construct correlation value (0.787). All in all, these results confirm the existence of discriminant validity of the measurement used in this study.

Table 3: Correlations between Constructs

\begin{tabular}{|l|c|c|c|}
\hline \hline Research Constructs & OS & TJS & TJP \\
\hline Organisational Support (OS) & 1.000 & & \\
\hline Teacher Job Satisfaction (TSS) & 0.634 & 1.000 & \\
\hline Teacher Job Performance (TJP) & 0.527 & 0.720 & 1.000 \\
\hline
\end{tabular}

Note: OS = Organisational Support; TJS = Teacher Job Satisfaction; TJP = Teacher Job Performance

\subsection{Path Model}

PLS also generates the path coefficients for the relationships modeled among the constructs. The significance of these coefficients was assessed using the bootstrap procedure (with 200 sub-samples) that provided the t-values for each path estimate. Figure 2 and Table 4 presents the results of the PLS analysis on the structural model along with the path estimates and t-values. Support for the study hypotheses, which are labeled on their corresponding paths in Figure 2, could be ascertained by examining the directionality (positive or negative) of the path coefficients and the significance of the t-values. The standardized path coefficients are expected to be at least 0.2 , and preferably greater than 0.3 (Chin 1998). 


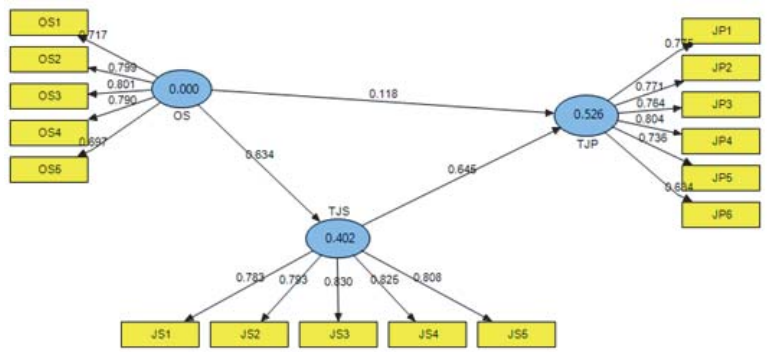

Note: OS = Organisational Support; TJS = Teacher Job Satisfaction; TJP = Teacher Job Performance

Figure 2: Measurement and Structural Model Results

The results provide support for the proposed positive relationships between the three relationships (i.e. $\mathrm{H} 1, \mathrm{H} 2$, and $\mathrm{H} 3$ ). However, results in Table 4, indicates that only three (i.e. $\mathrm{H} 3, \mathrm{H} 4$ and $\mathrm{H} 5$ ) of the posited relationships are statistically significant (i.e. T statistics value is greater than 2). Figure 2 and Table 4 provide the path coefficients for $\mathrm{H} 1, \mathrm{H} 2$ and $\mathrm{H} 3$ (i.e. $0.118,0.634$, and 0.646 respectively).

Table 4: Results of Structural Equation Model Analysis

\begin{tabular}{|l|c|c|c|c|}
\hline \hline Proposed Hypothesis Relationship & Hypothesis & Path Coefficients & T-Statistics & Rejected / Supported \\
\hline Organisational Support (OS) $\rightarrow$ Teacher Job Satisfaction (TJS) & H1 & 0.634 & 15.449 & Supported \\
Organisational Support (OS) $\rightarrow$ Teacher Job Performance (TJP) & H2 & 0.118 & 1.186 & Supported \\
Teacher Job Satisfaction (TJS) $\rightarrow$ Teacher Job Performance (TJP) & H3 & 0.645 & 8.281 & Supported \\
\hline \hline
\end{tabular}

Note: OS = Organisational Support; TJS = Teacher Job Satisfaction; TJP = Teacher Job Performance

Overall, $\mathrm{R}^{2}$ for TJS (0.402) in Figure 2, indicate that the research model explains more than $40 \%$ of the variance in the endogenous variables while TJP explains about $53 \%$ (0.526). Following formulae provided by Tenenhaus, Vinzi, Chatelin \& Lauro, (2005), the global goodness-of-fit (GoF) statistic for the research model was calculated using the equation:

\section{$\mathrm{GoF}=\sqrt{\mathrm{AVE}} \mathrm{R}^{z^{-}}$}

The calculated global goodness of fit $(\mathrm{GoF})$ is 0.47 , which exceed the threshold of $\mathrm{GoF}>0.36$ suggested by Wetzels, Odekerken-Schröder \& van Oppen (2009). Thus, this study concludes that the research model has a good overall fit.

\section{Discussion and Conclusion}

The purpose of this study was to investigate organisational support on teachers' job satisfaction and performance. In particular, three hypotheses were postulated. To test the proposed hypotheses, data were collected from university staff members in two South African Universities. The empirical results supported all the three research hypotheses in a significant way.

Important to note about the study findings is the fact that organisational support has strong effects on job satisfaction (0.634) than job performance (0.118). However, teacher job performance strongly influences their performance (0.646) more than what organisational support does $(0.0 .11)$. By implication, this finding indicates that organisational support has strong influence on job performance via job satisfaction. Perhaps this could be due to the fact that the effects of organisational support are likely to be teacher satisfying and ultimately the teachers are therefore motivated to perform better- which sounds logical.

\subsection{Implications of the study}

The ever-increasing importance of organisational support to teachers in South Africa cannot be over-emphasised. In particular, organisational support has been used to enhance teacher job satisfaction and to improve their performance during this era of educational transformation. The current study is an attempt to undertake a research in an often most neglected context but yet an important sector of the South African economy. Therefore, the findings of this empirical study are expected to have to provide fruitful implications to both practitioners and academicians.

On the academic side, this study makes a significant contribution to the organisational literature by systematically 
exploring the impact of organisational support on job satisfaction and performance of teachers. In particular, the current study findings provide tentative support to the proposition that organisational should be recognized as significant antecedent and tool to influence teachers' job satisfaction which will motivate them to improve their performance.

On the practitioners' side, important influential role of organisational support in South Africa's teachers is highlighted. This study therefore submits that organisational leadership should develop strategies to support teachers. When teachers perceive support from the organisations, they are likely to enjoy their job and consequently produce quality work. Furthermore, practitioners - for instance, managers who want to improve teacher performance, they ought to target organisational support interventions that are considered motivating for teachers.

\subsection{Limitations and Future Research}

In spite of the contribution of this study, it has its limitations which provide avenues for future researches. First and most significantly, the present research is conducted from the student perspective at two universities in South Africa. Perhaps if data collection is expanded to include other universities, the research findings might be more insightful. Future studies should therefore consider this recommended research direction. Second, the current study was limited to students in South Africa's Gauteng Province. Subsequent research should contemplate replicating this study in other provinces of South Africa or even other African countries for results comparisons. All in all, these suggested future avenues of study stand to immensely contribute new knowledge to the existing body of organizational behaviour literature, a context that happen to be less researched by some researchers in Africa.

\section{References}

Amin, S.S.S. 2013. The Impact of Organisational Support for Career Development and Supervisory Support on Employee Performance: An Empirical Study from Pakistani Academic Sector. European Journal of Business Management, 5(5(:194-207.

Abdullah, A., Bilau, AA, Eneghuma, W.I., Ajogbe, A.M. \& Ali, K.N. 2011.Evaluation of Job Satisfaction and Performance of Employees in Small and Medium Sized Construction Firms in Nigeria. $2^{\text {nd }}$ International Conference on Construction and Project Management, IPEDR 15, Malaysia.

Baranik, L.E., Roling, E.A. \& Eby, L.T. 2010. Why does Mentoring Work? The Role of Perceived Organisational Support. Journal of Vocational Behaviour, 76:366-373.

Bilgin, N. \& Demirer, H. 2012. The Examination of the Relationship among Organisational Support, Affective Commitment and Job Satisfaction of Hotel Employees. Procedia-Social and Behavioural Sciences, 51: 470-473.

Borgogni, L., Ruso, S.D., Petitta, L. \& Vecchione, M. 2010. Predicting Job Satisfaction and Job Performance in a Privatised Organisation. International Public Management Journal, 13(3):275-296.

Bowling, N.A. 2010. Effects of Job Satisfaction and Consequences on Extra-Role Behaviours. Journal of Business Psychology, 25:119-130.

Chiang, C.F. \& Hsieh, T.S. 2012. The Impact of Perceived Organisational Support and Psychological Empowerment on Job Performance. The Mediating Effects of Organisational Citizenship Behaviour, 31:180-190.

Chin, W.W, \& Newsted, P.R. (1999). Structural Equation Modeling analysis with Small Samples Using Partial Least Squares. In Rick Hoyle (Ed.), Statistical Strategies for Small Sample Research, Sage Publications, pp. 307-341. Thousand Oaks, CA: Sage

Chin, W.W. (1998). Issues and opinion on structural equation modelling, MIS Quarterly, 22 (1), 7-16

Chinomona, R. (2012). The impact of organizational support on work spirituality, organizational citizenship behaviour and job performance: The case of Zimbabwe's small and medium enterprises (SME) sector. African Journal of Business Management, 6 (36), 10003-10014.

Chinomona, R \& Surujlal, J. (2012). The influence of student internship work experience on their self-improvement and professionalism in Sport Management. African Journal for Physical, Health Education, Recreation and Dance (AJPHERD), 18 (4/2), 885-899.

Lu, H., Barriball, K.L., Zhang, X. \& While, A.E.2012. Job Satisfaction among Hospital Nurses Revisited: A systematic Review. Internatioanl Journal of Nursing Studies, 49:1017-1038.

Malhotra, N. \& Mukherjee, A. 2004. The Relative Influence of Organisational Commitment and Job Satisfaction on Services Quality of Customer-Contact Employees in Banking Call Centres. Journal of Services Marketing, 18(3):162-174.

Markovits, Y., Davis, A.J., Fay, D. \& Dick, R. 2010. The Link Between Job Satisfaction and Organisational Commitment: Differences Between Public and Private Sector Employees. International Public Management Journal, 13(2):197-196.

Miao, R.T. (2011). Perceived Organisational Support, Job Satisfaction, Task Performance and Organisational Citizenship Behaviour in China. Institute of Behavioural and Applied Management, 1:1-23.

Ng, T.W.H., Sorensen, K.L. \& Yim, F.H.K. 2009. Does the Job Satisfaction-Job Performance Relationship Vary Across Cultures? Journal of Cross-Cultural Psychology, 40(5):761-796.

Noblet, A.J. \& Rodwell, J.J. 3009. Identifying the Predictors of Employees' Health Satisfaction in a Npm. 11(5):663-683.

Rhoades, L. \& Eisenberger, R. 2002. Perceived Organisational Support: A Review of the Literature. Journal of Applied Psychology, 87(4):698-714.

Riggle, R.J., Edmondson, D.R. \& Hansen, J.D.2009. A Meta-Analysis of the Relationship between Perceived Organisational Support and Job Outcomes: 20 Years of Research. Journal of Business Research, 62:1027-1030.

Ringle, C. M., Wende, S., \& Will, A. (2005). SmartPLS 2.0 M3. Available at http:// www.smartpls.de

Tenenhaus, M., Vinzi, V.E., Chatelin, Y.-M., \& Lauro, C. (2005). PLS Path Modeling. Computational Statistics \& Data Analysis, 48 (1), $159-205$.

Way, S.A., Sturman, M.C. \& Raab, C. 2010. What Matters More: Contrasting the Effects of Job Satisfaction and Services Climate on Hotel Food and Beverage Managers' Job Performance. Cornell Hospitality Quarterly, 51(3):379-397.

Wetzels, M., Odekerken-Schröder, G., \& Van Oppen, C. (2009). Using PLS path modeling for assessing hierarchical construct models: guidelines and empirical illustration. Management Information Systems Quarterly, 33(1), 177-195. 